\title{
AGRESSIVIDADE E SOCIALIZAÇÃO EM CRIANÇAS COM TRANSTORNO DO ESPECTRO AUTISTA
}

\begin{abstract}
RESUMO
O Transtorno Espectro Autista (TEA), sendo pouco compreendido, tanto na sociedade quanto na educação, criando assim, uma visão equivocada em crianças com TEA, muitas vezes, colaborando com suas dificuldades de socialização, aprendizagem, comunicação, comportamentos repetitivos e interesses restritos, podendo apresentar sensibilidade sensoriais e no âmbito pessoal. A agressividade no TEA, não se restringe em uma única forma de tratamento, uma vez que, existem várias formas de agressão, variando-se de acordo com o indivíduo e seu meio, visto que este comportamento é muito mais acentuado em meninos do que meninas. Tendo em vista a falta de compreensão do TEA e as crises de agressividade causadas pelo transtorno, é de grande importância conhecer mais sobre o assunto, também nas áreas educacional e clínica, para melhor convívio social e intelectual, não só da criança com TEA, mas também, aos educadores e familiares, buscando sempre a independência da criança com TEA e a evolução do seu tratamento atraves da familia.
\end{abstract}

Palavras-chave: Transtorno Espectro Autista. Autismo. Agressividade. Crianças. Socialização. 


\section{INTRODUÇÃO}

Quando ouve-se dizer no termo "criança autista", logo vem em mente a imagem de uma criança solitária, vivendo no seu próprio mundo, permitindo-se estar distante de qualquer influência exterior, ou até mesmo, que ficam balançando seu corpo de um lado, para o outro, freneticamente.

Normalmente, associando-se como "diferente" ou fora da "normalidade". Mas não é bem assim, nem todas as crianças são completamente limitadas na sociedade, por adquirirem o Transtorno do Espectro Autista, podendo ter seu desempenho de forma significativa.

Em 1908, a educadora austríaca Heller descreveu seis crianças que apresentavam um quadro clínico muito estranho. O início dos sintomas se dava em torno do terceiro ou do quarto ano de vida, após período de desenvolvimento aparentemente normal, com mal-estar progressivo, rápida diminuição de interesse pelo ambiente e pelas pessoas, com perda de fala e de controle esfincteriano e regressão "idiótica" com preservação da fisionomia inteligente e do funcionamento motor grosseiro (STELZER, 2010, p. 07).

Segundo (STELZER, 2010, p. 08 apud BENDER, 1959) o autismo como um distúrbio da consciência no qual há desligamento parcial ou absoluto da pessoa em relação à realidade $\mathrm{e}$ a vida interior.

\section{TRANSTORNO ESPECTRO AUTISTA (TEA)}

A maior parte das crianças com TEA no geral, apresentam principais dificuldades na interpretação com os outros (comunicação sem palavras e a linguagem corporal), tendo um bloqueio significativo em fazer amizades. Além disso, são totalmente dependentes das rotinas e sensíveis a mudanças em seu dia-a-dia.

Tendo como definição os manuais médicos, Vicente et al. (2016), afirma que:

[...] o autismo, ou a Perturbação do Espetro do Autismo (PEA), é uma condição médica do sistema nervoso central que se manifesta na infância e que se caracteriza por dificuldades na comunicação e interação social e por 
comportamentos, interesses ou atividades repetitivos e estereotipados (Vicente, 2016).

Cada indivíduo com TEA, apresenta um ritmo diferenciado de aprendizagem, dentre eles a socialização, portanto, a inevitabilidade dos pais em se adaptar a esta condição, permitindo que se dediquem ao cuidado sobre as necessidades da criança com autismo.

Autismo justifica-se por conta da imensa variação de características clínicas que se observa. É incorreto dizer "a pessoa com autismo faz isso ou faz aquilo, deste ou daquele jeito". Algumas pessoas com autismo não falam, outras não param de falar, algumas falam de forma incomum, apresentam pouca compreensão, não compreendem, ou compreendem de forma única. Alguns indivíduos machucam a si próprios, outros machucam outras pessoas, muitos não machucam ninguém. (MELLO et al., 2013).

Muitas pessoas com autismo são extremamente rotineiras, outras não se importam tanto com isso, sendo assim, não se trata de um transtorno que se resolve com uma acomodação ou medidas de acessibilidade. (MELLO et al., 2013).

Segundo Mello et al. (2013), é possível afirmar que:

Trata-se de um universo imenso, com combinações únicas de dificuldades nas áreas de comunicação, interação social e motivação[...] todos esses indivíduos é que suas combinações únicas de características comportamentais são duradouras e afetam de modo significativo sua qualidade de vida e a de seus familiares (MELLO et al., 2013).

\section{AGRESSIVIDADE NO TEA}

Determinadas crianças com TEA por serem sensíveis a mudanças e entre outros fatores, podem gerar um impulso de agressão, muitas vezes, não apresentando motivos tão grave como elas consideram. Por ter uma dificuldade de percepção do mundo exterior, estando centrado em seu próprio universo, é complexo faze-la compreender que se agredir e agredir o outro não são comportamentos aceitáveis.

$\mathrm{Na}$ imagem abaixo identifica-se alguns possiveis estimuladores da raiva. 
Figura 1 - Possíveis desencadeadores da raiva.

\section{POSSÍVEIS DESENCADEADORES DA RAIVA}

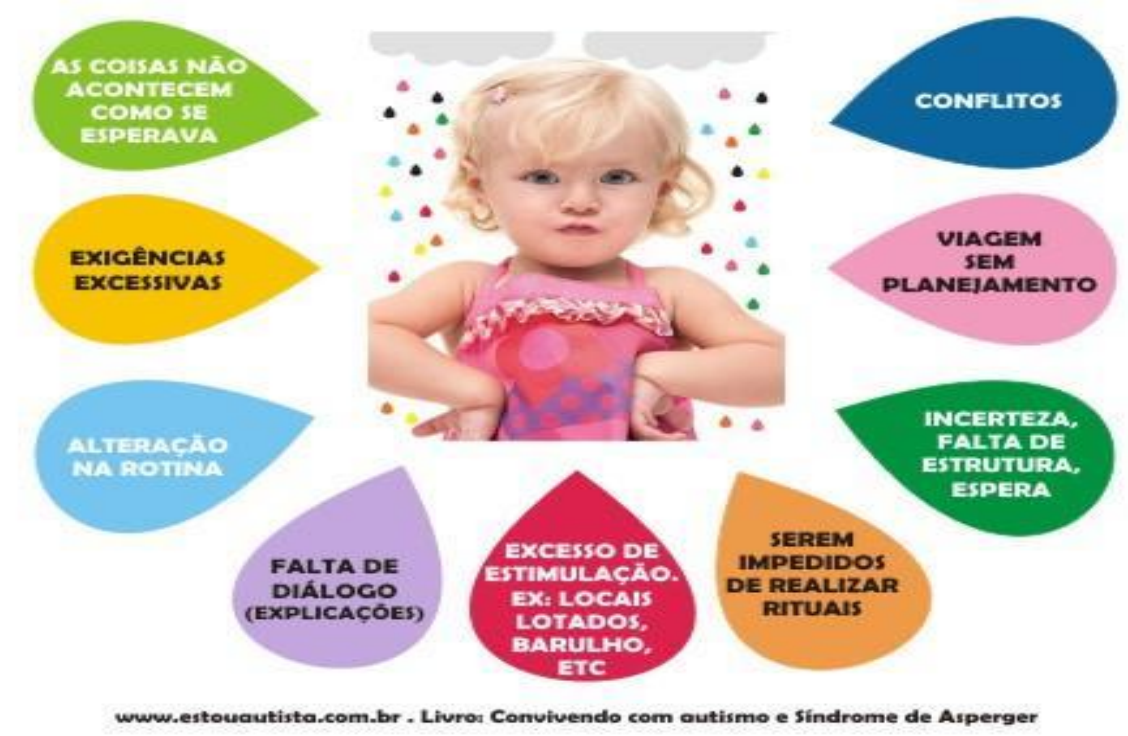

Fonte: ESTOU AUTISTA, 2013.

Algumas formas de lidar com a agressividade da criança com TEA é permanecer o mais calmo possível, sendo assim, impedindo que a criança eleve seu emocional, evitar o contato físico (a não ser que seja necessário), sempre tentar distrai-la da origem da raiva, estar disposto a caminhar e ouvi-la calmamente, sem argumentar sobre o acontecido, direcionar a criança a um lugar tranquilo e relaxante, proporcionar outros meios da criança liberar os sentimentos de raiva, por exemplo, rasgar papeis, o ato de ouvir músicas relaxantes, também auxilia no comportamento agressivo.

Se a fala não é uma opção disponível, outras formas de comunicação têm que ser exploradas. Não significa abandonar a linguagem falada, significa apenas oferecer uma alternativa que permita que o indivíduo consiga satisfazer suas necessidades, enquanto outras formas de comunicação não estiverem disponíveis, o ato de apontar, escolher, obter atenção, pedir ajuda, água, comida ou colo podem ter que ser direta e sistematicamente ensinadas, obtendo uma atenção mais direcionada, pois algumas ações comunicativas mesmo estabelecidas, podem ser tão básicas que são simplesmente insuficientes para lidar com certas condições.

Segundo Mello et al. (2013), temos por definição os seguintes exemplos: "a criança de desenvolvimento típico que pede o chocolate no supermercado, pode ficar perfeitamente satisfeita ao ouvir da mãe que há um saco de chocolates aguardando por ela no carro. Ou pode concordar em comer o chocolate depois do jantar.” Esse tipo de negociação envolve o uso de 
uma linguagem mais complexa que, muitas vezes, não está ao nosso alcance quando estamos diante de uma pessoa com autismo, sendo presente o comprometimento significativo da linguagem (MELLO et al., 2013).

Segundo Bandim (2010), revela o percentual do diagnóstico de nascimento da população de crianças com autismo:

\begin{abstract}
A frequência do autismo na população está entre $0,7 \%$ a $1 \%$, ou seja, para cada 10.000 crianças nascidas há 13 crianças autistas, no entanto, este percentual tende a crescer por inúmeras razões, dentre elas, a maior divulgação do autismo, a conscientização e habilidade no diagnóstico por parte da classe médica e a identificação precoce. A incidência é maior em crianças do sexo masculino e etiologicamente não existe "uma causa" para o autismo, o máximo que se tem proposto é a identificação de fatores genéticos e biológicos (BANDIM, 2010).
\end{abstract}

Figura 2 - Representação do ciclo da raiva

\title{
CICLO DA RAIVA
}

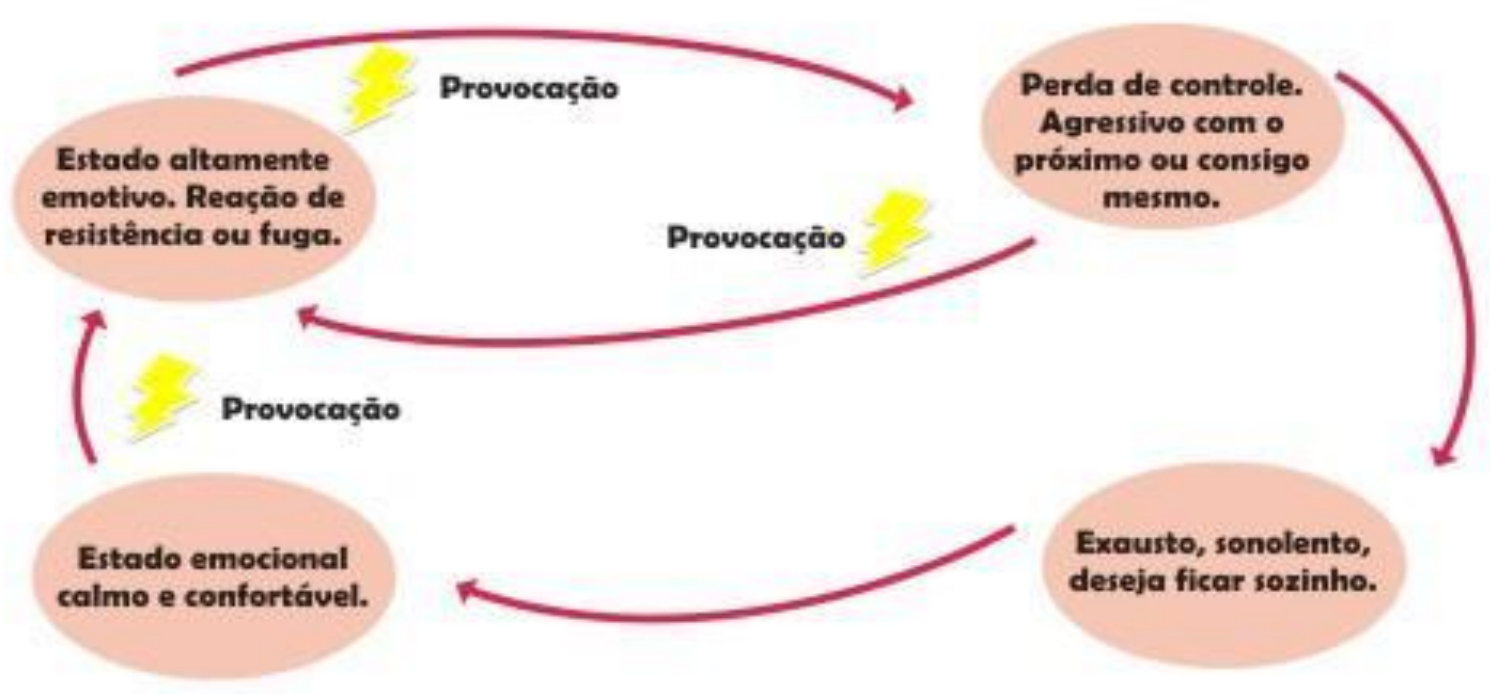

www.estouautista.com.br. Fig 12.1, pág. 182, Convivendo com autismo e Sindrome de Asperger

Fonte: ESTOU AUTISTA, 2013.

Como visto na imagem a cima, as pessoas neurotípicas costumam se queixar diante de alguma situação. Todos nós usamos as palavras, os gestos e até mesmo o olhar para reprovar aquilo que não nos deixa bem. Com os autistas isso nem sempre é possível. Muitos deles não 
têm esse domínio, o que ocasiona em uma chateação extrema. O resultado final é a agressividade, como o ponto máximo de estresse.

Cada paciente com autismo tem uma diferença. Existem aqueles que convivem com muita ou baixa capacidade sensorial (olfato, visão, paladar, audição, entre outros); junto dessa característica, a criança pode evitar qualquer coisa que cause sensação de aperto, literalmente falando (roupa colada e abraços) (MELLO et. al., 2013).

Por exemplo, o sujeito que esfrega constantemente o queixo no ombro, pode acabar produzindo uma imensa lesão nas regiões envolvidas, tendo em vista, algumas formas de estereotipia motora possibilitando um efeito autolesivo (MELLO et. al., 2013).

Em muitos outros casos é presente também o envolvimento de respostas autolesivas intensas (socos ou tapas no rosto, entre outros); não tem uma explicação concreta do motivo pelo qual, tais comportamentos autolesivos são estabelecidos. Têm-se hipóteses sobre as possíveis características sensoriais desse tipo de comportamento, umas delas é que a atenuação gradativa da dor que segue o comportamento autolesivo é prazerosa o suficiente para manter o comportamento de forma regular (MELLO et. al., 2013).

O que fazer quando a criança ou adolescente ficar agressivo?

a) Identifique algum sinal que possa significar o estresse, entre eles estão incluídos: cara fechada, tensão muscular, cabeça baixa, isolamento; (APAE BRASIL, 2018).

b) Afaste-o de ambientes tumultuados (com muitas pessoas ou ruídos); (APAE BRASIL, 2018).

c) Mantenha sempre a calma; (APAE BRASIL, 2018).

d) Não grite e não sacuda seu filho para repreendê-lo; (APAE BRASIL, 2018).

e) Tente criar um código de comunicação entre vocês para que a criança consiga se expressar, mesmo que por meio de gestos e expressões; (APAE BRASIL, 2018).

f) Não tente impor nada; (APAE BRASIL, 2018).

g) Em caso de birras ocasionadas por alguma negativa, ofereça alternativa ao pequeno; (APAE BRASIL, 2018).

h) Apresente algo que a criança goste: uma brincadeira, uma imagem, um joguinho, um desenho animado; (APAE BRASIL, 2018).

i) Ofereça um ambiente que seja confortável ao pequeno; (APAE BRASIL, 2018).

j) Podemos impedir que o comportamento agressivo produza a remoção da tarefa, tornando-o ineficiente. Seria inadequado - e é impossível enfatizar isso 
suficientemente - limitar a intervenção apenas à terceira estratégia. Mas ela poderia ser usada como um componente do tratamento quando o sujeito já dispuser de maneiras para se comunicar e/ou a tarefa em si não for mais tão aversiva (MELLO et. al., 2013).

k) Podemos tentar reduzir as características aversivas à tarefa em si, diminuindo o esforço necessário, seu grau de dificuldade, a duração, ou mesmo acrescentando características motivadoras à atividade (comida, carinho, atenção, brinquedos, etc.) (MELLO et. al., 2013).

Agressividade e TEA não são sinônimos Jamais devemos pensar que a agressão é uma peculiaridade do autista. O detalhe está em alguns fatores que podem ser completamente trabalhados a fim de que essa irritação seja diminuída.

Uma boa parte dessas crises de agressividade podem ser prevenidas, desaceleradas, sem que se transformem em emergências ao mesmo tempo a mesma estratégia pode ser adotada quando o comportamento problema pode-se obter as funções comunicativas. Segundo Mello (2013), usa como exemplo: "o sujeito que se bate para ganhar acesso a algo que deseja consumir, pode apresentar melhoras se souber comunicar seu interesse e se a relação entre bater e obter o que quer for quebrada ou enfraquecida." Partindo da ideia que o esforço é direcionado ao ensino de habilidades mais sutis, com intuito de proteção a própria criança e parte do esforço concentra-se no planejamento adequado de forma abrangente a forma como o indivíduo interage com o mundo ao seu redor. Porém, quando o comportamento é mantido por suas consequências automáticas ou efeitos sensoriais, esse tipo de abordagem tende a não funcionar. Nesse caso, alternativas sensoriais, e bloqueio ou restrição do comportamento são alternativas viáveis (MELLO et. al., 2013).

\section{INTERESSES COMO FORMA DE APRENDIZAGEM}

Como Orrú (2003), afirma em sua pesquisa, "Uma das responsabilidades do educador é a de intervir na vida humana por meio da reflexão e da ação reflexiva, geradoras de estratégias pedagógicas para o bem comum do educando.” logo, se é impossível fazer de conta que o autismo não existe, certamente podemos, enquanto educadores, nos dispormos à busca de maneiras inovadoras, facilitadoras, diferenciadas e produtivas para a construção de uma melhor qualidade de vida para a pessoa com autismo. 
Ainda referenciando Orrú (2003), temos a seguinte premissa sobre o universo dos educadores, "Esta não é uma tarefa fácil para o educador, no entanto, também não é impossível de ser realizada. O universo da educação de um aluno com autismo é, deveras, complexo para o abordarmos de forma singela.", logo, pode-se afirmar que

Toda a pessoa que se forma para assumir a responsabilidade de ser um educador precisa ser compromissado com a causa que faz dele um profissional. Porém, o educador que recebe um aluno com autismo em sua sala de aula necessita exercitar e preservar algumas características em sua personalidade como parte indissolúvel de seu compromisso com a educação (ORRÚ, 2003).

Todo educador tem um dever de assegurar a qualidade de ensino de seus alunos em sala de aula, mesmo que não seja uma tarefa fácil, ainda sim se tratando de um aluno com transtorno, é necessário tal apoio para melhor rendimento não só dentro da escola, mas também em seu tratamento e por meio do apoio familiar, proporcionando uma melhor capacidade de relacionarse.

\section{APOIO FAMILIAR}

O cuidado da criança com TEA exige da família um grande períodos de dedicação, provocando, em muitos casos, redução da carga horaria de trabalho, lazer e até de negligência aos cuidados da saúde dos familiares. Diante da necessidade dos pais e cuidadores, deve ser oferecido um espaço de escuta e acolhimento de orientação e até de cuidados terapêuticos específicos (MINISTÉRIO DA SAÚDE, 2013).

Através da família pode-se identificar a eficácia e evolução do tratamento recebido pelo autista, seja através da fala, da capacidade de relacionar-se, de realização de atividades domésticas corriqueiras como escovar os dentes, fazer xixi, alimentar-se, tomar banho, vestirse. A família é de grande importância na ajuda da inclusão da criança autista, num mundo onde ele não se vê, onde não se encontra e onde acha difícil comunicar-se. O interesse que os pais demonstram ter sobre seus filhos, claramente são refletidos nas crianças como segurança, motivação e amenização de dificuldades presentes. A inclusão deve começar em casa, compreende-se o transtorno da criança, sendo assim, estimular a melhoria do trabalho 
diariamente para que o quadro autístico tenha o mínimo de estereotipias e comprometimentos (PEREIRA, 2011).

Segundo Pereira (2011) comenta que a interação social é de suma importância no ambiente de desenvolvimento da criança com TEA...

[...] É importante que a criança seja inserida num ambiente estimulador de interação social, obviamente ultrapassando os limites do convívio familiar, o que pode acentuar manias, excitação emocional e agressividade (PEREIRA, 2011).

Toda criança precisa adquirir sua independência, através da valorização de experiências habituais, de contato social, aprendendo habilidades pessoais e domésticas, especialmente a criança com TEA que depende da interação social em atividade simples como calçar os sapatos, organizar os próprios brinquedos, arrumar a mesa antes das refeições. Têm um grande diferencial para a evolução do quadro de autismo, pois tira a criança do isolamento (PEREIRA, 2011).

Isolar a criança com TEA do convívio social é prejudicial, pois pode agravar a agressividade e outros comportamentos preocupantes, ela necessita de uma familiaridade com as atividades pessoais para adquirir uma independência significativa em sua vida.

\section{MÉTODOS QUE AUXILIAM O TEA}

A convivência com o autismo requer dos familiares e profissionais o conhecimento e utilização de alguns métodos e técnicas que facilitem a interação social com o portador desta síndrome. Vale salientar a existência de inúmeros métodos e sempre surgem novas tecnologias que facilita o desenvolvimento do autista, aqui será descrito alguns métodos utilizados corriqueiramente no Brasil atualmente, como o TEACCH, PECS, SONRISE e LIVOX.

Um dos métodos de ensino mais utilizados no Brasil para atender o autista é o TEACCH Treatmentand Education of Autistic andrelated Communicattion handicapped Children que foi desenvolvido no início de 1970 pelo Dr. Eric Schopler e colaboradores, na Universidade da Carolina do Norte (EUA). Os métodos ofertam o diagnóstico, auxilios aos pais e profissionais e centros comunitários para adultos com todas as etapas: avaliação psicológica, salas de aulas e programas para professores. O TEACCH é um programa de atendimento que envolve a psicologia comportamental e a psicolinguística, visa-se desenvolvimento e a independência do 
indivíduo de modo que necessite do professor para auxilio do aprendizado, mas que possa utilizar parte de seu tempo ocupando-se de forma independente (MELLO, 2013).

Outro método é o sistema de PECS - Sistema de comunicação por troca de figuras foi desenvolvido para ajudar crianças e adultos autistas e com outros distúrbios de desenvolvimento para estabelecer uma forma de comunicação para os autistas que não desenvolvem a linguagem, pois poucos autistas têm uma fala funcional e este recurso é um facilitador, permite que o autista se expresse mais para isto, é preciso que o autista possua um nível de compreensão mínimo (MELLO, 2013).

Atualmente, o programa Livox - Sistema de comunicação alternativa para tablets fornece uma solução para comunicação para pessoas com dificuldades na fala. O Livox oferece conversão de texto em voz com sons naturais, milhares de símbolos, personalização total e uma grande facilidade de manuseio em Tablets Android. Foi desenvolvido no Brasil por Carlos Pereira é considerado o primeiro sistema de comunicação alternativa totalmente na língua portuguesa (MELLO, 2013).

Son-Rise é um programa para tratamento de crianças com autismo, com uma abordagem relacional, onde a relação interpessoal é valorizada. O programa não é um conjunto de técnicas e estratégias a serem utilizadas com uma criança, mas um estilo de interação, uma maneira de relacionar-se e inspirar-se a participação espontânea em relacionamentos sociais (MELLO, 2013).

\section{O FUNCIONAMENTO CEREBRAL DE UM AUTISTA}

O autismo tem causas desconhecidas, considera-se uma anormalidade em alguma parte do cerébro que ainda não à definição conclusiva, provavelmente uma origem genética, sendo assim, é importante considerar o aspecto epidemiológicos e evolutivos, bem como todo o conhecimento disponível sobre as alterações moleculares relacionadas à doença, além disso, não descarta-se a possibilidade de ter causa por problemas relacionados a gestação ou no momento do parto (SERTIÉ, 2017).

Já que as causas são desconhecidas, o que é recomendado na prevenção do autismo são os cuidados gerais a todas as gestantes, especialmente os cuidados com ingestão de produtos químicos, tais como remédios, álcool ou fumo (MELLO, 2013).

O diagnóstico do TEA é clínico, feito a partir de observações da criança e entrevistas com os pais ou cuidadores, o que torna o uso de instrumentos de triagem e avaliação padronizados uma necessidade, a maior plasticidade das estruturas anátomo-fisiológicas do 
cérebro nos primeiros anos de vida, bem como o papel fundamental das experiências de vida de um bebê, para o funcionamento das conexões neuronais e para a constituição psicossocial, tornam este período um momento sensível e privilegiado para intervenções, o TEA também pode estar associado a distúrbios metabólicos em um número relativamente pequeno dos casos. Ainda que os distúrbios metabólicos encontram-se associados a um padrão de herança (sendo mais prováveis em casos de casamentos consanguíneos) e apresentarem características clínicas claras, como convulsões, regressão neurológica e outras alterações fisiológicas (SERTÍE, 2017).

Os proficionais de atuação da assistencia materno-infantil tem um papel vital na identificação de sinais de alterações no desenvolvimento da criança, ao longo dos anos, constatou-se que um número considerável de pacientes com TEA apresentava mutações raras com efeito deletério sobre o desenvolvimento neuronal, que seriam suficientes para, sozinhas, causarem a doença (SERTIÉ, 2017).

$\mathrm{Na}$ imagem abaixo, pode-se observar o tronco cerebral normal que possui o Corpo Trapezoide, Oliva Superor, Núcleo Facial, Núcleo Hipoglosso e Oliva Inferior, já no tronco cerebral de uma pessoa com espectro autista, é notavel a ausencia da Oliva Superior, a redução do Nucleo Facial, estando apenas presente o Corpo Trapezoide, Núcleo Hipoglosso e Oliva Inferior.

Figura 3 - Alterações no tronco cerebral

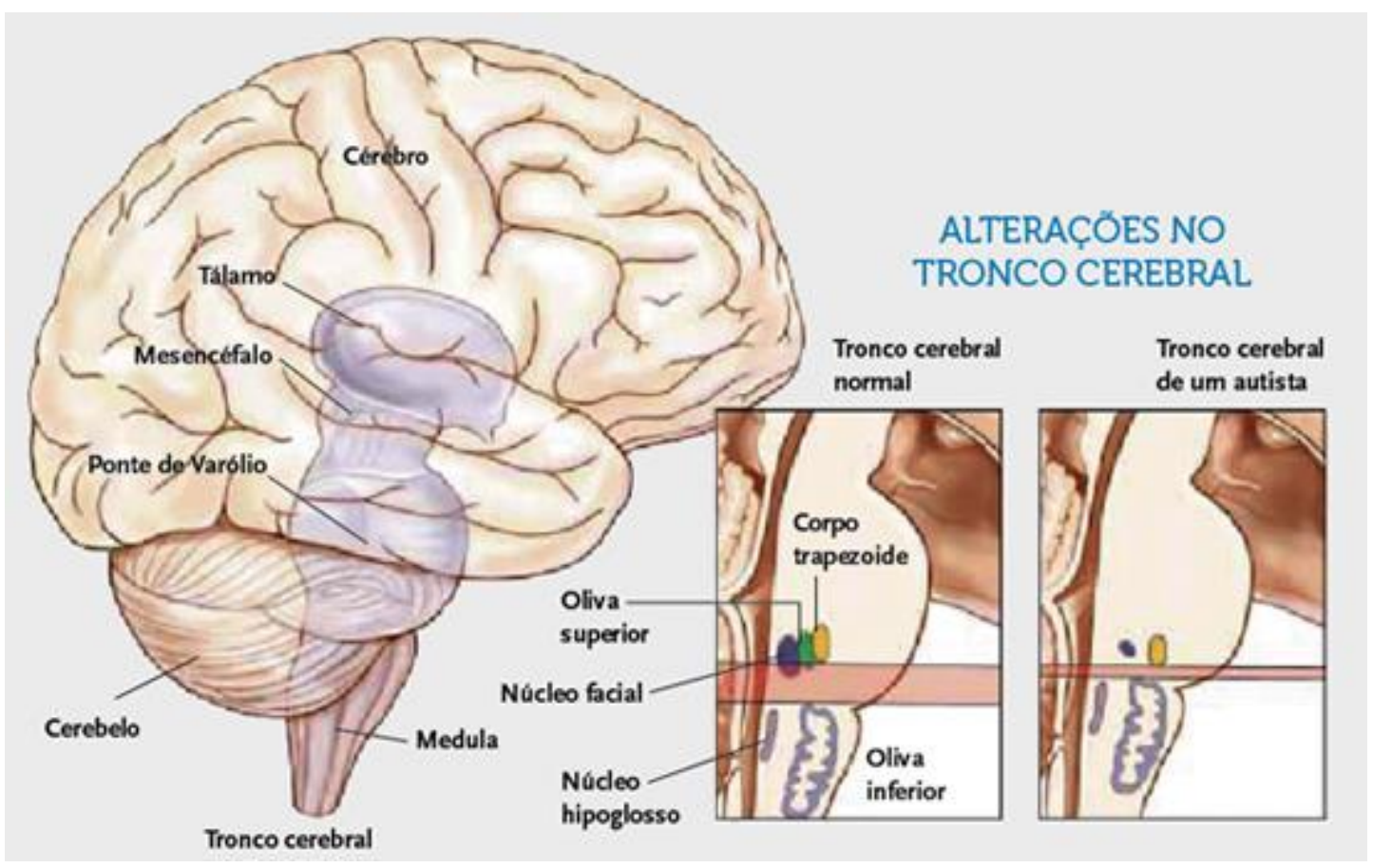

Fonte: Viver Mente e Cerebro, s.d. 
Sabe-se que manifestações do quadro sintomatológico devem estar presentes até os três anos de idade da criança, fator que favorece o diagnóstico precoce. É importante observar não somente a presença ou ausência de uma competência ou habilidade, mas sua qualidade e frequência nos contextos de vida das pessoas.

$\mathrm{Na}$ imagem abaixo, é apresentado um estudo americano sobre o conhecimento do autismo e uma forma de diagnosticar o transtorno, com base a comparação cerebral sem autismo e com autismo, a partir de métodos como ressonância magnética, apresentando baixa atividade cerebral em uma região específica chamada de Circuito de Percepção Social do Cérebro, sendo assim, acredita-se que seja possivel um inicio de tratamento mais cedo e com mais sucesso.

Figura 4 - Detecção precode do TEA

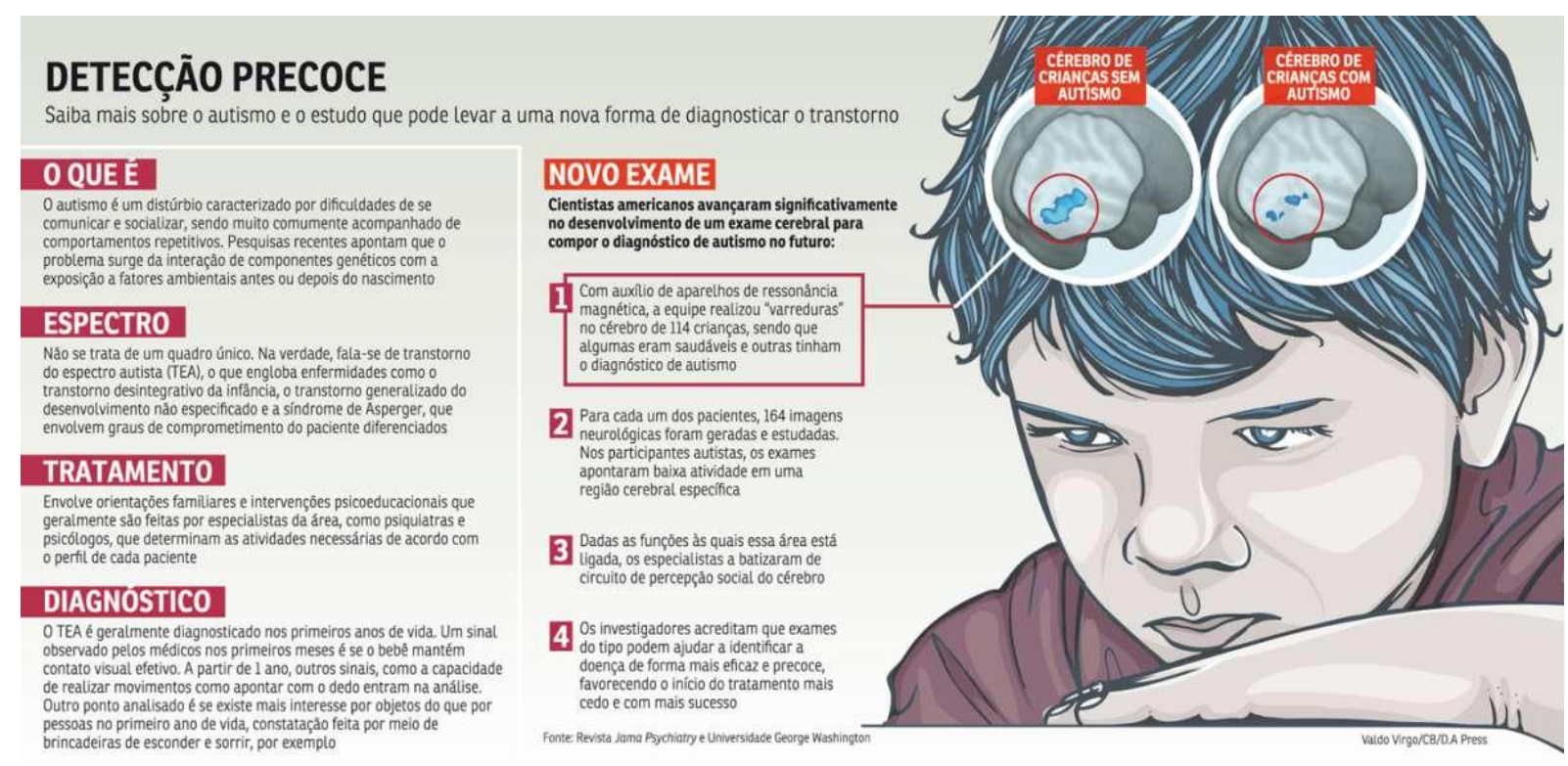

Fonte: Valdo Virgo/CB/D.A Press, s.d 


\section{CONCLUSÃO}

O conhecimento sobre o transtorno espectro autista é de suma importância para área educacional, sendo assim, os professores têm que lidar com uma vasta lista de complexidade dos alunos, entre elas, está o TEA. Grande parte das crianças com este transtorno, por serem voltadas ao seu mundo interiorizado, acabam se expressando através da agressividade e reclusão social, por tanto, os educadores, tem que estar preparados para trabalhar com esse tipo de relação, não só para o bem-estar da criança com TEA, mas também, com o desenvolvimento social em relação as outras crianças de sua turma. O professor é de extrema importância na vida do aluno, sendo visto como "modelo" a ser seguido, sendo assim, é importante que o professor conheça um pouco do seu aluno, para saber como ter um resultado significativo no desempenho escolar, tal ato que reflete também no desenvolvimento pessoal de cada criança, de forma que a mesma seja independente, visando o apoio familiar que requer grande dedícação, para assim analisar o rendimento da evolução do tratamento da criança com autismo. Com base em estudos extrangeiros, sabe-se diagnosticar o transtorno com a comparação cerebral de indivíduos com autismo e sem autismo, pois apresenta baixa atividade cerebral em uma região específica, sendo assim, acredita-se que seja possivel um unicio tratamento mais cedo e com mais eficácia. Têmse sinais do desenvolvimento infantis que pode ser utilizado como alerta para uma criança com TEA. As crianças com TEA tendem a um impulso agressivo por serem sensiveis a mudanças, entre outros fatores, algumas formas de amenizar esse estresse é afasta-lo de ambientes tumultuados (até mesmo de rúidos), tentar manter a calma para não repreendê-lo e criar um código de comunição entre a criança e o adulto, sendo assim, facilita a forma de se expressar da criança, mas sem tentar impor. 


\title{
AGRESSIVITY AND SOCIALIZATION IN CHILDREN WITH AUTISTIC SPECTRUM DISORDER
}

\begin{abstract}
Autistic Spectrum Disorder (ASD), being poorly understood in both society and education, thus creating a mistaken view in children with ASD, often collaborating with their difficulties of socialization, learning, communication, repetitive behaviors and restricted interests, sensory and personal sensitivity. The aggressiveness in ASD is not restricted to a single form of treatment, since there are several forms of aggression, varying according to the individual and their environment, since this behavior is much more pronounced in boys than girls. Given the lack of understanding of ASD and the attacks of aggression caused by the disorder, it is of great importance to know more about the subject, also in the educational and clinical areas, for better social and intellectual living, not only the child with ASD, but as well as to educators and families, always seeking the independence of the child with ASD and the evolution of their treatment through the family.
\end{abstract}

Keywords: Autism Spectrum Disorder. Autism. Aggressiveness. Children. Socialization. 


\section{REFERÊNCIAS}

VICENTE, Astrid Moura et al. O Autismo. Lisboa, Portugal: Instituto Nacional de Saúde Doutor Ricardo Jorge, IP, 2016. Disponível em: http://hdl.handle.net/10400.18/3444. Acesso em: 1 ago. 2019.

MELLO, Ana Maria et al. Retratos do autismo no Brasil. São Paulo - SP: Editora Talento, 2013. Disponível em:

https://www.autismo.org.br/site/images/Downloads/RetratoDoAutismo20131001.pdf. Acesso em: 1 ago. 2019.

BANDIM, José Marcelino. Autismo: Uma abordagem prática. Recife: Bagaço, 2010.

ORRÚ, Sílvia Ester. A formação de professores e a educação de autistas. Revista Ibero Americana de Educação, São João da Boa Vista, SP, 15 mar. 2003.

Disponível em: https://rieoei.org/RIE/article/view/2965. Acesso em: 1 ago. 2019.

PEREIRA, Cyelle Carmem Vasconcelos. AUTISMO E FAMÍLIA: PARTICIPAÇÃO

DOS PAIS NO TRATAMENTO E DESENVOLVIMENTO DOS FILHOS AUTISTAS.

FACENE, João Pessoa, Paraíba, 2011. Disponível em: http://atividadeparaeducacaoespecial.com/wpcontent/uploads/2015/08/AUTISMO-EFAMILIA.pdf. Acesso em: 1 ago. 2019.

STELZER, Fernando Gustavo. Historia autismo. In: STELZER, Fernando Gustavo. Uma pequena história do autismo. São Leopoldo: Editora Oikos, 2010. Disponível em: http://www.pandorgaautismo.org/includes/downloads/publicacoes/Pandorga-Caderno1.pdf. Acesso em: 19 mar. 2019.

ESTOU AUTISTA. Lidar com comportamento agressivo. [S. l.], 2013. Disponível em: http://www.estouautista.com.br/index.php/2013/11/22/lidar-com-comportamento-agressivo/. Acesso em: 20 mar. 2019.

APAE Brasil. COMPORTAMENTO AGRESSIVO NO AUTISMO? SAIBA O QUE FAZER. [S. l.], 21 fev. 2018. Disponível em: https://apaebrasil.org.br/noticia/comportamentoagressivo-no-autismo-saiba-o-que-fazer. Acesso em: 20 mar. 2019. 
MINISTÉRIO DA SAÚDE. Diretrizes de atenção: à Reabilitação da Pessoa com Transtornos do Espectro do Autismo (TEA). Brásilia - DF: [s. n.], 2013. Disponível em: https://www.autismo.org.br/site/images/Downloads/diretrizes.pdf. Acesso em: 20 mar. 2019. OLIVEIRA, Karina Griesi; SERTIÉ, Andréa Laurato. Transtornos do espectro autista: um guia atualizado para aconselhamento genético. Transtornos do espectro autista: um guia atualizado para aconselhamento genético, São Paulo / SP, p. 234-238, 4 maio 2017. Disponível em: http://www.scielo.br/pdf/eins/v15n2/pt_1679-4508-eins-15-02-0233.pdf. Acesso em: 20 mar. 2019. 